\title{
COSMIC SLOP: Possibilities of Alien Futures (From the Past)
}

\author{
Lina Nasr El Hag Ali \\ York University, Department of Politics \\ Ross Building, Room S672 \\ 4700 Keele Street, Toronto, ON \\ M3J 1P3, Canada \\ Ihash@yorku.ca
}

\author{
A.T. Kingsmith \\ York University, Department of Politics \\ Ross Building, Room S672 \\ 4700 Keele Street, Toronto, ON \\ M3J 1P3, Canada \\ atking@yorku.ca
}

\begin{abstract}
The elite imaginaries of our world hold a monopoly over the future, drawing power from the particular 'utopias' they promote as a kind of currency to induce a psychosomatic investment in a specific future of society. This displaces the material and temporal content of actually lived exploitation today. In considering the ways in which power now operates predictively as much as retrospectively, we explore the conditions for shaping an asymmetrical politics of transformation beyond the hyperbolic tropes of our current future. To this end, we argue that alien-theory can help to conjure new tomorrows through a focus on the creative power of non-being, disconnection, exploitation and alienation. In collecting together critical threads running through 'science fiction capital', cyborg theory, Afrofuturism and Xenofeminism, we synthesize a series of 'alien-on-earth' approaches to this futures-crisis in the context of a neoliberal present where our relationship with the experience of alienation has been fundamentally changed, altered and reformed. In speaking to the ways in which we can begin to decolonise this future-monopoly, we explore the concept of chronopolitics as a collective effort for unearthing different histories, mapping alternative spatiotemporalities and reshaping our present conditions in the now of time.
\end{abstract}

\section{Alien-theory. Futures-industry. SF Capital. Afrofuturism. Xenofeminism. Chronopolitics.}

\section{INTRODUCTION: WHEN IS THE FUTURE?}

To put it nicely, the future seems bleak. Much of our present imaginings of the what-is-to-come are plagued with visions of the apocalyptic. But as The Invisible Committee $(2015,1.3)$ aptly observes, "the purpose of [these] prophec[ies] is never to be right about the future, but to act upon the present: to impose a waiting mode, passivity, submission, here and now."

Throughout the 20th century, avant-gardists and cyber-feminists from Walter Benjamin and Frantz Fanon to Donna Haraway and N. Katherine Hayles revolted in the name of a future against power structures that relied on the control and representation of the historical archive. Today, this situation is reversed. The impossibility of imagining a future outside of our present political and economic conditions - and how that is reflected to us in the works of science fiction - functions as a site of key concern for us in this work (Žižek 2002, Jameson 2005, Fisher 2009, Vint 2016).

Our aim in this paper is to explore different ways of re-claiming the future as a space for greater social and ecological sustainability, but also the future as our capacity to imagine estranged and new worlds. This is in contrast to our current capitulation to the future as it is envisioned by global capital. In order to begin thinking of such futures beyond the 'now', we argue that it is imperative to dispense with the limitations of the human subject.

What we call for is neither an overcoming of organic-mechanic dualisms, nor the reversing of their rootings, but their necessary and totalising alienation. In doing so, we explore the possibilities of extra-terrestrial futures in which 'the alien', as a material-semiotic figure, can displace the dualisms encoded on the human: organic/cyborg, animal/ machine, body/mind, man/woman, utopia/dystopia, white/black, hetero/homo, etc. In this regard, the alien, unlike the hybridized subjectivity of the cyborg, functions as a vector of transvaluation: a force existing, or coming from somewhere beyond our current planetary-technological assemblages of future-control.

By probing the conditions of possibility beyond the hyperbolic tropes of the current futures on offer, we contend that alien-theory can help to conjure new tomorrows through a focus on the creative power of non-being, disconnection, exploitation and 
alienation. In collecting together these threads of critical inquiry, we attempt to synthesize a series of 'alien-on-earth' approaches to the politics of the future in the context of a neoliberal temporality where the future has become a site of crisis, both in the present - in the looming threats of climate change, environmental and species destruction, the rise of the Right in Europe, North America, India, the Philippines and elsewhere, and the immanent collapse of global financial markets - and in our capacity to imagine other possible worlds.

With such ends squarely in mind we ask: How can we redirect science fiction towards estranged new worlds rather than extending our current one? What could it mean for us to conceptualise the alien not as a fantastic fiction or an affect of exploitation but as a mechanism for generating new possibilities in the present? What can we do if we were to embrace the shared experience of alienation and even proliferate it further? In other words, how can the alien work as a vector for organizing against the intensification of anxiety, racism, paranoia, and precarity that has thrown out the promise of all possible futures, be they cyber-feminist, Black liberationist, social democratic or otherwise?

Addressing such questions necessitates a double move: tracing the co-optation of the cyborg present before redirecting our focus to alienated futures that are disorganized, noncoherent, nonhuman, and lacking, and thus do not function within the ambit of future-control. In considering the ways in which power now operates predictively as much as retrospectively - dissimulating historical archives by envisioning, managing, and delivering reliable futures - we conclude with a discussion of chronopolitics as a concept descriptive of a set of temporal practices that can be put to effective use (Virilio 1977, Eshun 1998).

In doing so, we argue that alienation cannot simply be reduced to the isolating, dehumanizing, and disenchanting effects of working within a capitalist system of production. By recognizing alienation as a universal condition among all non-normative subjects, we probe alien-theory as a strategy for forging new solidarities that can cut across static identity categories as a way to extend rather than limit. Importantly, this is not a call for the rewarming of intersectionality. But rather, for an active project of alienation that moves away from the privileged norms, bodies and histories that have become naturalized as 'the future', and towards a political orientation that slices through every particular by refusing the linear classification of temporality.

At stake, as van Veen (2015) discerns, is the recovery of past cycles of futurity and the derailing of the whitewashed, technocratic futures currently in effect. As corporations seek to manage the unknown through scenario-based decisions, while civil society responds to future shocks through habits formatted by science fiction, the covenants of the alien, marginalized within literature and yet central to modern thought, can be mobilized as a program for recovering the histories of counterfutures and as a space for the critical work of manufacturing tools capable of destabilizing the neoliberal futures industry.

\section{THE FUTURES INDUSTRY}

In fashioning the future, science fiction as both a literary tradition and an industry, is a primary site of future-control and its reproduction. This also makes it a primary site for power.

When we look to the future we see only more of the present, more of the same capitalist values and sites of invisibility, while the actual present pales in comparison to the techno-product-saturated future to which we aspire, (Vint 2016). When this future is routinely invoked to obscure the present in all its anxiety and exploitation, the power of falsification, the drive to rewrite reality, and the will to produce all plausible alternatives becomes fundamental, not trivial, (Eshun 2003).

Given this context, it would be naïve to understand science fiction, located within the expanded field of the futures industry, as merely a projection into the far future, or as a utopian project for imagining alternative social realities. As Liu (2016) observes, across the spectrum of popular science fiction, the future no longer functions to prompt us to imagine something other than the present but simply exists as the spectre of its intensification.

As a mode of future-production, Fisher (2009) terms this kind of thinking science fiction capital or 'SF capital'. Under the conditions of SF Capital, we seek simply to survive, to endure, and are no longer capable of imagining that there is an outside or alternative.

By distancing the economic, social, and political conditions of the now-here and no-where, the world is rendered by capital as simply 'the world', not one social alternative among many, but an indeterminacy that defuses anything unstable that might explode (Hoffman 2016). This synergy - a utopian feedback of future oriented media and capital - encourages us to place our material investment in only a narrow range of futures that are produced by corporations as the chief mechanism by which we are encouraged affectively to invest in the possibilities of capitalism.

The triumphant 'end of history' in the West, as considered by Brown (2015), has culminated in a 
loss of conviction about the capacity to craft and steer our existence or even to secure our future. As Vint (2016) reiterates, this is the most profound and devastating sense in which modernity is 'over'. Ceding all power to craft the future to cybernetic algorithms, SF Capital insists that markets 'know best', even if, in the age of financialisation, markets do not and must not know it all, and the hidden hand has gone permanently missing. This lost present is stretching, slipping for many into yesterday, reaching for a privileged few into tomorrow.

\subsection{Futures Made of Silicon (Valley)}

SF capital works by giving expression to a futurity that is already implicit within the present moment. And while science fiction does not claim to actually predict the future, what it projects or extrapolates is a kind of virtual future. That is to say, as Shaviro (2010) points out, it explicates (literally unfolds) the anticipations - or the shards of futurity - that are lurking within our actual social experience.

Since the 1980s, this actual social experience of the future has been dominated by a global orthodoxy that serves to naturalise a libertarian science-fantasy that actively forecloses all possible alternative futures. As early as 1995, Barbrook and Cameron characterised this orthodoxy as 'the Californian Ideology' - in honour of the U.S. state where it originated - an assertion that social and political debates about the future have now become meaningless.

By arguing that only the cybernetic flows and chaotic eddies of free markets and global communications will determine the future, these Californian ideologues underpin the de-politicising forces of SF Capital. Alternative economic and political imaginations are seen as a waste of resources. As libertarians, they assert that the will of the people, mediated by participatory and diverse imaginaries of the future, is a dangerous heresy that interferes with the natural and efficient freedom to accumulate property. As technological determinists, they believe that human social and emotional ties obstruct the efficient evolution of the machine (Barbrook and Cameron 2015).

As Kriss (2017) points out, when situated in the context of industries that actively over-determine which futures are possible, Elon Musk's project of Martian colonisation is symptomatic of this silicon future. Musk's corporate practices are not utopian, nor are they world-building. As is indicative of the longstanding relationship between science, capital and power, the work of Space X and other 'private' research endeavours are made possible largely by government contracts (Sassower 2015).
But what is seemingly never asked are those questions that ultimately expose the future as the subjugation of present realities. Who is going to go to Mars? Is it Musk? Philanthro-capitalists like Musk? What historical, ideological, patriarchal, and colonial visions of society will they take with them? As Albanese $(1996,59)$ observes, we must not only consider science, fiction and capital as isomorphic modes of power, but also the role of colonial violence as mutually constitutive and interdependent, "given [its] intermittent re-articulation within successive cultural formations".

Considering the relationship between the silicon future, imperialism and colonialism, Kern (2003, 92) notes how the "annexation of the space of others" and the "outward movement of people and goods" has amounted to "spatial expressions of the active appropriation of the future". That colonialism, SF capital and power are fellow-travellers is indicated by a casual reflection on the popular tropes of science: to seek new vistas, explore new fields, go where no 'man' has gone before.

\section{HYPERNORMALISING THE CYBORG}

Cycling back from the colonial fantasies of Mars to the cyborg possibilities of the 1990s, it has become clear that the effect of SF capital has been to fuel the desire for a technological boom through informal descriptions in "science-fiction cinema, science-fiction novels, sonic fictions, religious prophecy, and venture capital" (Eshun 2003, 290). In Haraway's $(2003,60)$ own words, the inherent techno-utopianism built into policy and entrepreneurial research projects means that the cyborg is no longer a sufficient locus for interpreting the contemporary political moment: "by the end of the millennium, cyborgs could no longer do the work...to gather up the threads needed for critical inquiry".

The imminent danger of terrestrial devastation, technological determinism and social inequality that characterise the 'naturalized future' drove Haraway from the cyborg and into animal-human companion-ships that offer new possibilities for a post-industrial world. Whereas the infamous 'Cyborg Manifesto' (1985) decried the blockages imposed in a world thoroughly changed by the specific political and techno-scientific constellation of the Cold War, the future-control of the present no longer operates through containment, but by generating an attachment to the compromised conditions of silicon futures. Strict boundaries have fallen away as the possibilities for modification, communication, and motion are established and expanded through the impetus to 'express oneself' within the pre-determined mechanisms of 'consumer choice'. 
In this sense, cyborgs today have little to do with subversion and everything to do with modelling and predicting variation over time by oscillating between speculation and determinism, (Eshun 1998). While attention spans become 'hyperattentive' through accelerated flows of information across screens, and fleshy bodies become cybernetic through biosensors and self-quantification, so to do social relations become distributed across the atomised and entrepreneurial metrics that characterise the material and temporal conditions of SF capital. As Fernandez (2001) observes:

If the original radicality of Haraway's cyborg lay in its illegitimacy, the ubiquity of digital, exmilitary, and genetic technologies suggest that the cyborg is now a recognised legal citizen, much more a creature of social reality than of fiction. The utilisation of the cyborg as an image of edgy radicalism was, and still is, the territory of electronics and the fashion industry. As cyberfeminism emphasises the cyber and backpedals the feminism, the most radical politics of the manifesto have been largely ignored.

Haraway's prediction that control strategies applied to bodies - giving birth to new human beings would be developed using the Californian-language "of goal achievement for individual decisionmakers" had, by the beginning of the new millennium, all too fully borne out. Intergalactic colonisation, financial derivatives, genetically engineered seedlings, cloud computing, and biotechnological futures "are at once products of the new capitalist world order and the engines driving it”, (Tally 2013, 78).

From the cathedrals of Silicon Valley to the big data server farms of the Government Communication Headquarters $(\mathrm{GCHQ})$, the future-present has become an uninterrupted act of exalting the cyborg society and celebrating its myriad of connectivity. For a small segment of the world's population the Musk's of the world who have access to the medical services and technologies to repeatedly 're-generate' themselves at will - the conditions of this cyborg future have indeed been affirming and empowering. For the rest, the techno-utopian possibilities of the present serve to cultivate fears and anxieties amid mass surveillance, and the increasingly xenophobic and nationalistic politics of what Latham (2016) describes as the postglobalization era.

\subsection{Arrivals from Outer Space}

The non-linearity of Past-Future-Present is particularly important for the ways in which the material conditions of the past pre-configure the future. Whereas the trajectory of the cyborg follows from a linear model of progression (human- machine-hybridisation), the alien is out of synch with natural time: it arrives at the present through our futures-past. While the cyborg is half-human and half-machine, the alien is neither. As a mutable architecture that remains available for perpetual modification and enhancement, the alien pre-dates the discoveries of the hybrid, the machine, and even the human altogether.

Like the cyborg did for the particular techno-political constellation of the Cold War era, the alien addresses what Gilroy $(2013,271)$ underscores as the fundamental lack of an adequate conceptual and critical language for engaging with the "density of today's mixed and always impure forms". As a subject, a migrant, a foreigner, an affect, an aesthetic, a relation to the mode of production and more - through the alien we can move beyond the normalisation of the cyborg's present-past relationship with the antagonisms of silicon futures. After all, the alien is simultaneously 'not of this world' and also an 'alien-on-earth', characterised by the histories, peoples, events and practices submerged and displaced by the monopoly powers of particular whitewashed linear pasts, futures and presents.

Against such currents, the arrival of the alien seizes alienation as a creative force for generating new worlds. Instead of dividing subjects into intensely localised nodes within a large grid of identities, the alien draws our attention to the fact that almost everyone is alienated from everyone else and in just about every way. In this regard, our alien displacement of the cyborg as a trangressive material semiotic figure is important because alien theory problematises any positive affirmation of identity - as even post-human categories are often defined against the human they are not, cyborg theories can function to indirectly resuscitate a sort of 'critical' humanism by producing particular bodies, identities, and histories that reproduce the dualisms we nod to earlier.

By refusing the human (and by extention the cyborg) as a central analytic category, the alien provokes a fresh orientation: what Eshun $(1998,3)$ describes as a vector that can "design, manufacture, fabricate, synthesise, cut, paste and edit a so-called artificial discontinuum for the future [rhythm-machine]". In demanding alien listeners who can hear another world, the alien speaks not only to the ubiquity of alienation, but its very necessity. Drawing from the Afrofuturism and Xenofeminism of elsewhere, alien theory reminds us that we are all alienated, but also, that we have never ever been otherwise.

The condition of alienation - introduced by Marx (1939) as the abduction or estrangement from a 'species-being' that is always determined in a specific social and historical formation - is a 
psychosocial inevitability that all Afrodiasporic art uses to its own advantage by creating contexts that encourage a process of rethinking the relationship between politics and alienation (Blackman 2017).

After all, it is true that Marx conceptualised human alienation as the reification of human and social relations caused by commodity relations. However, Marx made this reduction only in so far as the essence of the matter was concerned - even in a capitalist society, the concept of alienation embraces a wider field than that of 'reification' or 'commodity fetishism' (e.g. the alienation of socially possible futures, alienation from the recognition of alterative histories, alienation from non-Western temporalities, etc.). In this sense, the problem is not alienation per se, but the ways in which our present experience of alienation is confined within a particular socio-economic imaginary.

The Afrodiasporic and Xenofeminist emphases on practices and forms that do not conform to specific semiotics and identities initiates an alien politics by exposing how the inhuman already exists within what counts as human life, even if submerged, occluded, disavowed and disqualified, (Goodman 2012). For instance, in speaking of the history of 'Black Music', Eshun (1998) describes the works of Coltrane, Sun $\mathrm{Ra}$ or Underground Resistance as alienating itself from the human, arriving from the future of non-being and non-coherence.

As the Xenofeminist collective 'Laboria Cuboniks' $(2018,1)$ makes clear, it is through and not despite our alienated condition that we can free ourselves from the "muck of immediacy" that defines the normalisation of the cyborg through SF Capital. In contrast to the libertarian techno-determinism of silicon futures, the alien's arrival from outer-space takes freedom not as given - and certainly not given by anything 'natural' - but as a process that involves the intensification of different forms of alienation. In accepting nothing as permanent neither historical conditions nor social forms - the alien mutates, navigates and probes every horizon.

To this end, alienations' critical necessity lies in its ability to assemble conceptual approaches and counter-memorial practices that re-move and put back into circulation previously inaccessible alienations. In this way, the radical opportunities afforded by developing (and alienating) forms of technological mediation are no longer put to use in the exclusive interests of capital, which, by design, only benefits the few (Hester 2018). Rather, as a means to reprogram the present, alien theory is neither utopian nor forward-looking, (Gibson 1984). By engineering feedback between imagined futures and a becoming-present, an alien sense of temporality can generate an artificial discontinuum to cut through the silicon futures of ubiquitous sameness, symmetry, and individuated affirmation.

\section{CHRONOPOLITICS}

As we move from a discussion of the normalisation of Haraway's cyborg embodiment of hybridity to a focus on chronopolitics as a dissipation from the outside in, we conclude by probing processes in which the alien, taken as a force existing, or coming from somewhere beyond, functions as a temporal vector for unsettling what we take bodies, communication, fiction, music and politics to be in the here and now.

After all, as anyone who has been deemed 'unhuman' or 'unnatural' in the face of reigning biological norms, anyone who has experienced injustices wrought in the name of the particular technological futures of SF capital, will realise the valorisation of the cyborg today has less and less to do with 'us' - queer, non-white, and trans bodies among us, the differently-abled - and everything to do with repackaging the possibilities of other worlds as an intensification of the same heteronormative, neo-colonial and technocratic presents regenerated by SF capital.

Centring the choronopolitics of alien time, we probe these other future-worlds through discourses of the "future as indifferent towards the human" (Ferrara 2012). As an alternative to the limitations of the linear past-present-futures terrain, chronopolitics meaning the politics of time - emerges not only as a critique of the whitewashing of the past, but as an active generator of future narratives. As alienation and temporality are entangled with one another, it is through chronology and causality, duration and frequency, continuity and discontinuity, that alien histories produce temporal meaning.

Alienation always works through both retrospection and anticipation, uniting the three elements of the time continuum (past-future-present). Simply put, a vision of the future is filtered by past experiences; our understanding of the past is constituted through that very future vision. In this regard, chronopolitics enables us to mark the present, that point in time that has always already passed or not yet come, through delimitating it from a retrospective past and an anticipated future.

As a political vector for recovering and generating new temporalities, van Veen $(2015,80)$ describes this process of enacting Chronopolitics as:

(i) Intervening in the production of collective memory - institutional, pedagogical, epistemic and museological histories, oral traditions and myths - and also schematic 
projections of the future. This collective memory is inscribed in texts, cultural practices, and technological objects.

(ii) Temporally producing counter-memories and counter-realities to combat corporate, techno-capitalist futures of dystopia-asutopia. A historical recovery operation, in which erasures and evacuations of the unwanted, insurrectionary, or traumatic past - the life of the alien-on-earth — are uncovered and put to use, in the responsibility towards the not-yet.

What might these alien temporalities look like? In contrast to the silicon futures that impose a spatiotemporal consciousness of time as the now of inevitable progress and growth - metrics that depend on some specific clock time or calendar date - Phillips (2016) points to what Mbiti (1990) calls 'potential time', where time itself depends on the quality of the event and the bodies and spaces experiencing it. Once the future event is experienced, it instantaneously moves backward into the present and past dimensions, destabilising the mechanical, progressive, unidirectional order of temporality.

Importantly, this chronopolitical sense of potential time is already being mobilised to revise hegemonic accounts of slavery, colonialism, and capitalist modes of production, rewriting these traumas by seeding not only alternate futures but recursive pasts for alienated subjects who have been overdetermined by what Sun Ra terms 'the manufactured past' (Eshun 2003). We offer two prominent examples.

First, the Kurdish liberation struggle (i.e. the People's Protection Union or 'YPG' in Rojava, also known as the 'Democratic Confederation of Northern Syria') can be understood in terms of alien time through its refashioning, cutting, pasting and synthesizing of elements of Bookchin's (2005) ecological anarchism to generate its own historical narrative. In marking the struggle for Kurdish independence as decentralised, anti-statist and feminist, this vision of their society takes aim at the past in order to insert in it the tools needed for the present-future.

Second, the 'degrowth' movement in political ecology can be understood as an alien praxis for producing knowledge critical of the ideology and costs of growth-based development. In this way, as Bollier (2009) points out, 'degrowth' signals a radical political and economic re-organisation that aims to destabilise linear notions of progress underpinning increasing resource and energy use. By dislodging the central analytical category of the Anthropocene, degrowth explores present-futures in the absence of growth. In doing so, their project calls not for the implementation of better, 'more progressive', futures-based development, but the decolonisation of the social and temporal imaginary from economic growth altogether (Latouche 2010).

Against the growth-driven orientation of naturalised, silicon futures, which are underpinned by the cyclical re-inscription of class, poverty, oppression, racism, violence against women and the legacy of slavery, the chrono-politics of the YPG, the degrowth movement, and elsewhere reminds us of the political importance of presentism over futurism. As Philips (2016) reiterates, such potentials can be operationalised against a myriad of communal trauma under conditions of class warfare and racial oppression by reengaging with the alternative temporal-spatial consciousness of alien time.

\subsection{We Are All Made of Stars}

The inevitable consequence of the silicon futures illustrated by SF Capital are what Toffler $(1970,11)$ called 'Future Shock': the "shattering stress and disorientation that we induce in individuals by subjecting them to too much change in too short a time". For Toffler, the greatly accelerated rate of social and technological change in our society has undoubtedly produced negative personal and psychological consequences by way of the superimposition of future-control over all other possible futures.

As we have emphasised throughout this paper, such future-shocks are not only a problem for the alien-on-earth, the marginalised Black, queer, differently-abled bodies most vulnerable to the affects of future-control. Apart from a few elites (i.e. Musk and company) we are all alienated from access to the supposed leisure, luxury and fulfilment of the future, stuck planning for a permanently disjointed present while the society around us speeds forward towards illusory, linear progress.

In this sense, the silicon-elites in our world hold a monopoly over the future, drawing power from the particular 'utopias' they promote as a kind of currency to induce a psychosomatic investment in a specific future of society. We have argued that this displaces the material and temporal content of actually lived exploitation today. As futureenterprises like Space $X$ sabotage alternative futures, responding to future shocks by drawing the unforeseeable back into tangible realities, in which one can invest in and 'bank on - very much in the spirit of stock market 'futures' - we call forth the possibilities of the alien for a future-now, a reengineering of the past brought about by a creative expansion of the scope of temporality. 
Jameson (2005, 228) echoes Benjamin's (1936) notorious observation that 'not even the past will be safe' from the manufacturers of history, adding: "the future is not safe either" from "the elimination of historicity, its neutralization by way of progress and technological evolution". The urgent need for a genuine re-imagining of the manufactured past so as to unlock alternate futures, the need to reclaim the power to imagine the future outside of industryproduced advertising images and experiences that is what the practice of alien theory is about.

For those of us who consider ourselves to be politically invested in the project of the future, recovering alternative futures of potential temporalities is a necessary task. Crucially, such a chronopolitics is a process of repurposing, not an outright rejection of the motifs of the past.

We are not saying we simply need more stories, more fictions. What we need is the conjuring of other worlds. This work is being done. In this regard, 'Cosmic Slop' is the messy entanglements cutting across all the different vectors presently working to transplant the cultural, political and technological spaces of the future into the past so as to be able to access them in the present. What we need are frameworks of reference to actualise our potential futures. Such work is being done in fields and spaces that are not typically understood to generate explicit political projects. This includes non-Western science fiction, Afro-diasporic design and creation, critical engineering, art and aesthetics.

We began this paper by asking: when is the future? By moving from SF capital's silicon futures through the cyborg, the alien, and finally, the politics of the chronos we have attempted to show that this 'when' is an endlessly postponed future-control that continues to produce unequal, predictable futures set against a forward moving time-line - one that will eventually come to a climactic, chaotic end.

In speaking to the ways in which we can begin to decolonise this future, we have emphasised the collective effort required in unearthing different histories, mapping alternative spatio-temporalities and understanding our present conditions in the now of time. By actively adopting alternative alienating orientations and frameworks, saturating our praxis in the cosmic slop provides a perpetual bridge between the past, future and present that can be used as liberation technologies to build future worlds.

To this end, what we are advocating for is the integration of aesthetics, politics, and technology towards re-envisioning and refashioning the past and the future - potential temporalities that are transgressive largely because they allow us to think and experience beyond the current limitations of thought, imagination and their materialising.

\section{REFERENCES}

Albanese, D. (1996) New Science, New World. Duke University Press, Durham, NC.

Barbrook, R. \& Cameron A. (1995) The Californian Ideology. Mute Magazine. http://www.metamute.org /editorial/articles/californian-ideology (29 May 2018).

Barbrook, R. \& Cameron A. (2015) The Internet Revolution: From Dot-com Capitalism to Cybernetic Communism. In G. Lovink \& M. Rasch (eds.), Network Notebooks. Institute of Network Cultures, Amsterdam.

Benjamin, W. (1936) Art in the Age of Mechanical Reproduction, In W. Benjamin Illuminations, Random House, London.

Blackman, L. (2017) "Loving the alien": a postpost-human manifesto. Subjectivity, 10(1) pp.1325.

Bollier, D. (2009) The Stirrings of a 'Degrowth Movement' On the Commons. http://www.onthe commons.org/stirrings-degrowthmovement\#sthash. 5jlhXYzr.4wA2iRs0.dpbs (31 May 2018).

Bookchin, M. (2005) The Ecology of Freedom: The Emergence and Dissolution of Hierarchy. AK Press, Oakland.

Brown, W. (2015) Undoing the Demos: Neoliberalism's Stealth Revolution. Zone Books, New York.

Eshun, K. (1998) More Brilliant Than the Sun: Adventures in Sonic Fiction. Quartet Books, London.

Eshun, K. (2003) Further Considerations on Afrofuturism. CR: The New Centennial Review, 3(2), pp.287-302.

Ferrara, B. (2012) "My measurement of race is rate of vibration": Afrofuturism and the 'molecularization' of race. Dark Matter, 9(2).

Fernandez, M. (2001) Whatever Happened to the Cyborg Manifesto? Mute Magazine. http://www. metamute.org/editorial/articles/whatever-happenedto-cyborg-manifesto (27 April 2018).

Fisher, M. (2009) Capitalist Realism: Is There No Alternative? Zero Books, London.

Gibson, W. (1984) Neuromancer. Ace Books, New York.

Gilroy, P. (2013) Between Camps: Nations, Cultures and the Allure of Race. Taylor \& Francis: New York. 
Goodman, S. (2012) Sonic Warfare: Sound, Affect, and the Ecology of Fear. The MIT Press, Cambridge, MA.

Haraway, D. (1991) The Cyborg Manifesto. In D. Haraway, Simians, Cyborgs, and Women: The Reinvention of Nature, Routledge, New York.

Haraway, D. (2003) The Companion Species Manifesto: Dogs, People, and Significant Otherness. Prickly Paradigm Press, Chicago.

Hester, H. (2018) Xenofeminism. Wiley, London.

Hoffman, T. (2016) No Exit, Postmodern Style. CTheory: Theory, Technology, Culture, 38(3).

Jameson, F. (2005) Archaeologies of the Future: The Desire Called Utopia and Other Science Fictions. Verso Books, New York.

Kern, S. (2003) The Culture of Time and Space, 1880-1918. Harvard University Press, Cambridge, MA.

Kirss, S. (2017) A Repellent Musk. Current Affairs. https://www.currentaffairs.org/2017/07/a-repellentmusk (30 May 2018).

Latham, R. (2016) The Politics of Evasion: A PostGlobalization Dialogue Along the Edge of the State. Routledge, New York.

Laboria Cuboniks (2015) Xenofeminism: A Politics for Alienation. http://uberty.org/wp-content/uploads/ 2015/06/xenofeminism.pdf (25 May 2018).

Latouche, S. (2010) Farewell to Growth. Polity Press, Cambridge, UK.

Liu, K. (2016) Invisible Planets: Contemporary Chinese Science Fiction in Translation. Macmillan, Basingstoke, UK.

Marx, K. (1939) Grundrisse: Foundations of the Critique of Political Economy. Penguin Books, New York.

Mbiti, J.S. (1990) African Religions \& Philosophy. Heinemann Publishers, Portsmouth, $\mathrm{NH}$.

Phillips, R. (2016) Future. In K. Fritsch, C. O'Connor \& A.K. Thompson (eds.), Keywords for Radicals: The Contested Vocabulary of LateCapitalist Struggle. AK Press, Oakland, CA.

Sassower, R. (2015) Compromising the ldeals of Science. Macmillan, Basingstoke, UK.

Shaviro, S. (2010) Post Cinematic Affect. Zero Books, London.

Tally, R. (2013) Utopia in the Age of Globalization: Space, Representation, and the World-System. Macmillan, Basingstoke, UK.

The Invisible Committee (2015) To Our Friends.

The MIT Press, Cambridge, MA.
Toffler, A. (1971) Future Shock. Bantam Books, New York.

van Veen, T. (2015) The Armageddon Effect: Afrofuturism and the Chronopolitics of Alien Nation. In R. Anderson \& C.E. Jones (eds.), Afrofuturism 2.0: The Rise of Astro-Blackness. Lexington Books, New York.

Vint, S. (2016) Introduction to The Futures Industry. Paradoxa, 27(1).

Virilio, P. (1977) Speed and Politics: An Essay on Dromology. The MIT Press, Cambridge, MA.

Žižek, S. (2002) Welcome to the Desert of the Real!: Five Essays on September 11 and Related Dates. Verso Books, New York. 